\title{
Aristoteles und Horaz und ihre Bedeutung für das Literaturverständnis der Neuzeit
}

\author{
(vorgetragen in der Plenarsitzung am 16. Juli 2010)
}

\section{Arbogast Schmitt}

Seit ihrer „Wiederentdeckung“ (richtiger: Neurezeption) in der Renaissance hat die „Poetik“ des Aristoteles die europäische Literatur in der Theorie wie in der Praxis der Dichter für mehr als zweieinhalb Jahrhunderte maßgeblich beeinflusst. Aristoteles hatte, so glaubte man, der Dichtung die Aufgabe gestellt, die Natur nachzuahmen. „Natur“ sollte die geordnete Natur, der „Kosmos“, sein. In Übereinstimmung mit der biblischen Überzeugung, Gott habe alles nach Maß, Zahl und Gewicht geordnet (Sap. 11,20), empfahl noch die Aufklärungspoetik guter Literatur die Orientierung am „Buch der Natur“, da die freie Erfindung nur „Abgeschmacktes“ (Gottsched) zustande bringen könne. Die Ästhetik des 18. Jahrhunderts bricht mit dieser Tradition. Die neue Lehre ist, dass nicht die Natur der Dichtung, sondern das künstlerische Subjekt in schöpferischer Erfindung der Natur die Regeln gibt.

Erstaunlicherweise ist von einer Nachahmung der Natur in der „Poetik“ des Aristoteles nicht die Rede. Die Formulierung stammt aus der „Physik“ und bezieht sich dort eher auf das, was wir heute Technik nennen. In der „Poetik“" verwendet Aristoteles einen rein formalen Nachahmungsbegriff, der lediglich festhält, dass jede Kunst ihre Gegenstände in einem Medium darstelle. Ob diese Gegenstände erfunden oder der Wirklichkeit entnommen sind, stellt Aristoteles ausdrücklich frei, er begrenzt aber den Gegenstandsbereich: Dichtung solle - mögliches oder wirkliches - menschliches Handeln darstellen. Diese Begrenzung erschien schon den Literaturtheoretikern des Hellenisums (v. a. der Stoa und des Epikureismus) nicht mehr einleuchtend. Horaz, der diesen hellenistischen Theorien folgt, universalisiert den Bereich der Dichtung wieder: sie befasst sich mit denselben Gegenständen wie die Wissenschaft und die Philosophie (socraticae chartae), aber auf andere Weise. Sie stellt das Allgemeine in konkreter Anschauung (proprie communia dicere) und in passenden Gefühlen dar. Ihre Ordnung gewinnt sie durch die Orientierung an der Einheit und Ganzheit der „Natur“ ihrer Gegenstände. Dieses Dichtungsverständnis hatte die 
Renaissance lange vor der „Wiederentdeckung“ der „Poetik“ rezipiert. Die meisten Kommentatoren der „Poetik“" waren überzeugt, bei Aristoteles eine lediglich systematischere Erklärung eben dieser Auffassung von Dichtung zu finden. So wurde auch er zum Zeugen, dass Dichtung die natürliche Ordnung der Dinge nachahmen solle. Da der Dichter dies nicht mit den diskursiven Mitteln rationaler Wissenschaft, sondern in unmittelbar einfühlender Intuition tut, erschien die Dichtung als die überlegene Form der Welterkenntnis (im Ganzen), der Dichter als ein alter deus. Da diese theologisch-metaphysische Überhöhung der Dichtung einer der wesentlichen Gründe für die Abwendung von der „aristotelischen “Nachahmungspoetik wurde, ist es interessant, durch den Blick zurück auf Aristoteles zu sehen, dass man die Besonderheit dichterischer Produktion auch auf andere, weniger theologisierte Weise begründen konnte. Die Beschränkung auf den handelnden Menschen ist bei Aristoteles eine Begrenzung nicht des Gegenstandsbereichs, sondern unseres Zugangs zur Welt. Wer handelt, erstrebt etwas für sich Gutes, d.h., er erstrebt es mit Lust oder meidet es mit Unlust. Der Handelnde betrachtet die Welt, in moderner Begrifflichkeit, unter einem Gefühlsaspekt. Sofern ein solches Handeln nach Aristoteles nur bereits geformten, selbständigen Charakteren möglich ist, bringt die Darstellung einer Handlung eine strukturelle Ordnung der Teile zum Ganzen mit sich und bestimmt auch die Art des Stils der Darstellung, der dem Charakter gemäß sein muss. Deshalb sagt Aristoteles vom Dichter, er solle darstellen, wie ein Mensch von bestimmtem Charakter auf Grund eben dieses Charakters wahrscheinlich oder notwendig ganz Bestimmtes sagt oder tut. Dieses „Sagen oder Tun“ solle er vorführen, d. h. „nachahmen“, nicht abstrakt beschreiben.

Nachahmung hat hier den doppelten Sinn, dass der Gegenstand in einem Medium präsent ist, dass er aber auch nur in diesem Medium, d. h. durch die Handlungsdarstellung selbst, präsent sein soll. Aristoteles' Verständnis von Dichtung vermeidet so eine Abhängigkeit von Normen, Regeln und Vorschriften, d.h. eine „epistemische Reduzierung“ und einen überhöhten Anspruch auf eine allgemeine Weltweisheit des Dichters. Sein Konzept ist elastischer und subjektiver zugleich. Angesichts der Tatsache, dass die „neue" Ästhetik des 18. Jahrhunderts „die Ordnung der Dinge“ von der äußeren in die innere Natur des Subjekts verlegt und dadurch immer noch in Abhängigkeit vom Dichtungsverständnis der Renaissance blieb, bietet Aristoteles ein Verständnis von Dichtung, das den Gegensatz von (subjektiver) Fiktion und (objektiver) Nachahmung auf eine bedenkenswerte Weise unterläuft. 